\title{
Tragedia en el hospital de niños Manuel Arriarán: "Porque murieron por nosotros, siguen viviendo entre nosotros". Mártires de la Cirugía Infantil chilena
}

\author{
FRANCISCO BARRERA Q.
}

1. Jefe Servicio Pediatría Hospital Clínico San Borja Arriarán.

\begin{abstract}
Martyrs of the Chilean Pediatric Surgery: the tragedy at the Manuel Arriarán Children's Hospital. "Because they died for us, they still live among us.
\end{abstract}

Hace 50 años sucedió una de las más grandes tragedias en los hospitales chilenos, quizás la mayor que registra la Anestesiología mundial, duro aprendizaje y con alto costo en vidas humanas.

Ese día lunes 6 de mayo de 1963, en los momentos en que la menor de 5 años J.S.P. entraba en camilla a la sala de operaciones del pabellón del Hospital Manuel Arriarán, 1legó su madre. Venía caminando desde la calle Manuel Antonio Tocornal, cercana al hospital, pensativa y preocupada por la salud de su hija. La madre le preguntó a su hija ¿qué quieres? La pequeña Julita cerró sus ojitos y le dijo "un besito". Fue lo último que supo de su hija, portadora de secuelas de poliomielitis y en tabla de pabellón para una segunda cirugía correctora de sus secuelas en extremidades inferiores. La enfermera apuró el paso para que la pequeña entrara al pabellón. Seis médicos y siete auxiliares de enfermería preparaban en silencio el material para la operación. Dos grandes lámparas iluminaban las dos mesas de operación que disponía el pabellón. En la otra, está el niño E.S.C. de 9 años de edad, que ya llevaba más de 20 operaciones por malformaciones de extremidades inferiores, pero esta sería la últi- ma y tal vez podría caminar con mucha menor dificultad. Su madre lo movilizaba en los tranvías de la época, desde el barrio Independencia hasta el hospital. En tan largos y tantos sacrificados viajes pensaba en casi un milagro: "Tal vez más adelante nos permitan a las madres de los niños hospitalizados permanecer con ellos durante el día e incluso en la noche, ahora debo viajar desde lejos para verlo sólo unos minutos y a través de un frío vidrio de la ventanilla". Frente a cada mesa quirúrgica un equipo constituido por el cirujano, su ayudante, arsenalera, auxiliar y un médico "volante". Todo listo, con el silencioso ritual típico de los pabellones de hospital de aquella hermosa época.

En medio del silencio expectante, el Dr. Olimpo Molina Valdés ordena:

"Pueden empezar a colocarle el ciclo...".

En la mesa del lado sur va a iniciar su trabajo el Dr. Enrique Zabalaga Justiniano, con el joven y promisorio Dr. Alfredo Raimann Neumann de ayudante, anestesista el Dr. Mario Torres Kay. En la otra mesa, al costado norte, el Dr. Olimpo Molina V., sonríe amistosamente a su colega diciéndole "te veo animoso". El Dr. Jaime Palominos Zúñiga responde "siem-

Recibido el 9 de marzo de 2013, devuelto para corregir el 30 de marzo de 2013, segunda versión el 16 de abril de 2013 , aceptado para publicación el 13 de mayo de 2013.

Este trabajo cumple con los requisitos sobre consentimiento /asentimiento informado, comité de ética, financiamiento, estudios animales y sobre la ausencia de conflictos de intereses según corresponda.

Correspondencia a:

Francisco Barrera Q. 
pre estoy asi'”. El aparato de anestesia en esta mesa es manipulado por una joven y encantadora doctora, Ana María Juricic Villalón, quien recientemente había contraído nupcias con el distinguido y joven pediatra Patricio Hevia Rivas. Ambos pacientes duermen bajo anestesia. De pronto, un estampido seco, luego otro y otro. El pabellón se convierte en un infierno de destrucción y muerte y las esquirlas saltan cual bomba de racimo.

Eran las 8.55 horas de la mañana de ese día lunes 6 de mayo de 1963. Una llamarada azul se escapa por las ventanas del tercer piso del hospital, hacia la calle Sta. Elvira, escuchándose el estampido y visualizándose las llamas hasta doce cuadras de distancia. Dentro del hospital, cunde el pánico y llanto desconsolado en los más de 100 niños hospitalizados en el servicio de Cirugía infantil. El pabellón y parte del tercer piso destrozados y en su interior, catorce personas yacen heridos, algunos de muerte o ya fallecidos.

El Dr. Alfredo Raimann N., fue uno de los pocos que pudo sobrevivir con lesiones leves. Al sobrevenir el estallido cayó al suelo y ello lo salvó de una muerte cierta, las esquirlas pasaban por arriba de su cuerpo. La tabla quirúrgica de ese día consideraba 14 operaciones.

La investigación no fue del todo concluyente, pudo haber sido un defecto de la válvula de uno de los balones de ciclopropano, con escape de gas que al entrar en contacto con la electricidad estática produjo la explosión o con la chispa de un bisturí eléctrico. Aunque la humedad de esos días hacía improbable un fenómeno de electricidad estática.

Ya había información disponible que el ciclopropano (fórmula química C3 H6) el cicloalcano más simple, es altamente inestable e inflamable, cuya fórmula molecular consiste de tres átomos de carbono unidos entre sí formando un anillo, y cada átomo de carbono está unido a dos átomos de hidrógeno. Las uniones o ligaduras entre los átomos de carbono son mucho menos fuertes que una típica unión carbono-carbono. Esto se debe al ángulo de $60^{\circ}$ entre los átomos de carbono, que es mucho menor que el ángulo normal de $109,5^{\circ}$ de las uniones entre átomos con orbitales $\mathrm{sp}^{3}$ híbridos. La tensión en este ángulo debe ser sus- traída de la energía de unión normal C-C, por lo que el compuesto químico resultante es más reactivo que un alcano acíclico y otros cicloalcanos tales como el ciclohexano y el ciclopentano. Desde el punto de vista de la tolerancia era muy superior al cloroformo, tan usado en esa época, pero potencialmente muy peligroso. Siete accidentes habían ocurrido en el país hasta esa fecha, el más grave en abril de 1945 en el Hospital del Salvador.

El recuento inicial era de cuatro fallecidos y doce heridos, algunos de ellos con extrema gravedad, luego fallecerían otros dos médi$\cos .$.

Recuerda el Dr. Carlos Gutiérrez Ravello, joven cirujano en esos tiempos: "Observé al Dr. Alberto Veloso N., jefe del Servicio integrado de Cirugía infantil (Cirugía, Ortopedia, Quemados) apesadumbrado y con profundo dolor por los desgraciados hechos que le tocó vivir. Definido por los que le conocieron como el "Maestro y amigo incomparable", tendría muchas satisfacciones a futuro, pero siempre teñidos de un manto de tristeza. Sin embargo, en su interior ya pensaba como poder superar el infortunio y reorganizar el servicio de Cirugía infantil”. El Dr. Alberto Veloso Novoa fue reconocido posteriormente como "Maestro de la Cirugía Pediátrica Chilena".

El Dr. Alberto Salamon Igaz señalaba: " $\mathrm{Al}$ berto Veloso tuvo durante el transcurso de su vida satisfacciones por todo lo que merecidamente logró; pero también sintió el dolor profundo por hechos que desgraciadamente le tocó vivir. Uno de ellos fue la explosión del pabellón de operaciones de nuestro querido Hospital Arriarán, que provocó la muerte de cuatro jóvenes colegas y dos pequeños pacientes que estaban en el quirófano; además de invalidar y lesionar gravemente a otros dos colegas y a cinco auxiliares de enfermería. Esta desgracia caló muy hondo en la sensibilidad de Alberto, ya que impotentes vimos desaparecer uno a uno a nuestros queridos compañeros. Sin embargo, el Dr. Veloso supo sobreponerse a este enorme dolor y logró reorganizar nuevamente el Servicio en mejores condiciones que antes de la tragedia".

Continúa el Dr. Gutiérrez "El pabellón de operaciones, situado en la parte central del 
$3^{e r}$ piso, estaba constituido por una antesala de lavado y preparación de material y se continuaba con el quirófano que era una sala amplia con 2 mesas de operaciones colocadas paralelamente a unos 2 ó 3 metros de distancia. La anestesia la daban enfermeras, usando éter en un aparato de Ombredanne o cloroéter, en mascarilla denominada en aquella época «a la reina» en circuito abierto. El olor a éter era tan intenso que después de una mañana en Pabellón, los Cirujanos quedábamos impregnados de su olor por el resto del día.

Describir el dantesco cuadro que presenciamos es imposible ante tanto estruendo $y$ dolor. Ver a todos nuestros amigos y colegas prácticamente destrozados y con graves quemaduras, mientras continuaban explotando los frascos de éter y las llamas aún no se apagaban.

El trágico balance fue: 6 muertos en forma inmediata o a los días siguientes, después de una prolongada agonía. Los dos pequeños pacientes fallecieron en forma instantánea. De los 4 médicos: la Dra. Ana María Juricic, joven y promisoria colega, que se iniciaba en la práctica de anestesia, fallece a los pocos minutos, al estar al lado del tubo que explotó primero. El Dr. Mario Torres K., magnifico anestesista y gran compañero de trabajo, cuyas heridas y quemaduras lo llevaron a la muerte a la semana siguiente. El Dr. Enrique Zabalaga, eminente traumatólogo, con lesiones abdominales y de pelvis que terminaron con su vida. El Dr. Jaime Palominos, joven y talentoso cirujano de 27 años, cuyas lesiones abdominales y torácicas le provocaron la muerte antes de 24 horas.

Además quedaron con lesiones graves pero felizmente no mortales: el Dr. Olimpo Molina, eminente traumatólogo, con sección del paquete vasculo-nervioso de la axila que aunque fue intervenido de inmediato, quedó con graves secuelas que le inutilizaron en forma definitiva la extremidad superior derecha. El Dr. Alfredo Raimann N., con sección de tendones flexores de una mano que fue necesario intervenir, logrando un excelente resultado funcional, lo que le ha permitido llegar a ser una autoridad en malformaciones y patología de cadera, reconocido mundialmente. Para muchos es considerado el Padre de la Ortopedia chilena.

Además todo el personal que se encontraba en el pabellón sufrió lesiones de diversa gravedad, aunque no mortales. Sin embargo, varias de ellas invalidantes, 2 amputaciones de piernas, lesiones y secuelas de quemaduras que dejaron para siempre la huella indeleble de esa trágica mañana, que afectó a nuestro hospital y provocó gran conmoción y duelo en el pais e internacionalmente.

Es necesario recordar los nombres de todos los colegas fallecidos, porque ellos son sin duda los mártires de la Cirugía Pediátrica Chilena".

El Dr. Santiago Rubio Arce, connotado pediatra, Premio Julio Schwarzenberg Löbeck 1982 y futuro Jefe de servicio del mismo Hospital Arriarán, Maestro de la Pediatría chilena, recuerda entre sus vivencias:

"Cuantas alegrias, cuanto sufrimiento, cuanta historia, cuanto sentimiento conservo de mi Hospital Arriarán. En ese centro asistencial me desempeñé durante cuarenta años (1942 a 1982), teniendo la mayor satisfacción por haber conseguido sólo amigos y haberme retirado rodeado de su cariño sincero, tanto colegas como otros funcionarios. Tuve la oportunidad de vivir muchos hechos felices y algunos muy tristes".

Continúa el Dr. Rubio en su relato:

"Dentro de los hechos que me provocaron profunda tristeza puedo mencionar especialmente el cuarto y trágico suceso, que no puedo dejar de recordar acaeció el día 6 de mayo de 1963. Me encontraba en una sala de la Unidad de Lactantes A, analizando y examinando con los alumnos del Curso de Pediatría a un paciente que habia ingresado en la tarde del día anterior. Ese ha sido el día más amargo y doloroso que he tenido en mi vida profesional y laboral, tanto que 40 años después aún siento pena y como que un calofrio me recorre el cuerpo.

De repente sentimos un gran estampido o ruido y vimos que salía humo por las ventanas del pabellón de operaciones del Servicio de Cirugía y los vidrios saltaban en todas direcciones. Nos dirigimos corriendo de inmediato hacia ese lugar. Al llegar nos encontramos 
con el Dr. Olimpo Molina que rodaba por la escala, con su cuerpo y cara ensangrentados y exclamaba "arriba, arriba, arriba". Le acomodamos lo mejor que pudimos y seguimos subiendo, nos encontramos con otro colega (el Dr. Alfredo Raimann N), también herido pero no de tanta gravedad y pedía tener cuidado por temor a una segunda explosión.

Al entrar al pabellón nos encontramos con el escalofriante cuadro: Los dos niños que se iban a operar estaban muertos en la mesa de operaciones, la Dra. Ana María Juricic (anestesista), al lado de los niños, falleciendo a los pocos instantes; el Dr. Jaime Palominos, herido de muerte, nos miró y exclamó " $m i$ guatita”, falleciendo pocos instantes después. También estaban los Drs. Enrique Zabalaga y Mario Torres heridos de gravedad, falleciendo pocos días después a pesar de los cuidados prodigados en la Asistencia Pública. Hubo otras personas (auxiliares de enfermería y servicio), que sufrieron heridas, pero sin riego vital".

En las conversaciones sostenidas con el Dr. Rubio, aún mantenía una expresión triste y acongojada y le veía transportarse a esa triste mañana.

Connotada actuación en las tareas de controlar la explosión y posterior incendio le cupo a las Compañías de Bomberos del sector, particularmente a la Décima Compañía de Bomberos "Bomba España" de Avenida Matta, creando un lazo imperecedero que se mantiene hasta hoy, haciéndose presente siempre para esta fecha y también para la Navidad un cuerpo de voluntarios de la bomba en las antiguas dependencias del Hospital Manuel Arriarán.

La Sociedad Chilena de Anestesiología, (cuyo Presidente en ejercicio era precisamente el Dr. Mario Torres Kay, fallecido en el accidente) formó una comisión que emitió el informe "Condiciones de seguridad para la administración de agentes anestésicos volátiles y gaseosos" presentado en Asamblea el 17 de mayo de 1963 y cuyo estudio demostró otros siete accidentes ocurridos en el país hasta esa fecha, concluye: "Sería absurdo seguir usando ciclopropano sin tomar las precauciones exigidas en otros países. La primera medida por lo tanto parece obvia: suspender el uso de ciclopropano". Se hizo notar que, en ese tiempo en Chile, sólo los hospitales privados de Chuquicamata y Sewell cumplían con todas las normas de seguridad de EE.UU. para el uso de anestésicos y explosivos.

Este terrible accidente llevó a que se hiciera una profunda revisión de los riesgos en un pabellón de operaciones. Participaron en ella, el Ministerio de Salud, el Servicio Nacional de Salud, Colegio Médico de Chile, sociedades científicas, asociaciones gremiales, Cámara de diputados y el Senado.

Se prohibió el uso de ciclopropano en todos los hospitales del país y se hizo una acuciosa investigación de las causas de la explosión, para que ello no volviera a repetirse. Como el recinto del pabellón quedó inutilizado, se construyó uno nuevo en el ala oriente del tercer piso del Pabellón Errázuriz, con 4 quirófanos independientes, sala de anestesia y recuperación con 12 camas. Se tomaron todas las medidas preventivas: uso de nuevos gases de anestesia y colocados en una pieza aislada, enchufes eléctricos a mayor altura, prohibición de uso de material de "nylon" para evitar la electricidad estática. Con la ayuda de instituciones extranjeras se dotó de nuevas máquinas de anestesia, aspiradores y elementos de seguridad. Todo esto llevó a que después de un tiempo se volviera a la normalidad y continuara el avance en nuevas técnicas e intervenciones más complejas.

La prensa de la época señalaba profusamente el desgraciado accidente y sus implicancias, destacando el alto grado de compromiso de los médicos fallecidos, como se frustró su brillante futuro profesional y el lamentable y trágico deceso de dos niños.

\section{Datos biogróficos de los médicos fallecidos}

\section{Doctora Ana María Juricic Villalón}

Hizo sus estudios en el Colegio de los Sagrados Corazones. Se graduó el año 1953. Desde sus años de estudiante secundaria, siempre mostró predilección por seguir Medicina, una vez que ingresara a la Universidad, a pesar de que, igualmente, le agradaba el Ballet.

En 1954 ingresó a la Escuela de Medicina 
de la Universidad de Chile, oportunidad en que también conoció a otro estudiante que, como ella, soñaba con llegar a ser médico. Era Patricio Hevia Rivas, quien sería su esposo con el transcurrir del tiempo.

Vivieron ambos una etapa hermosa de estudiantes. Fueron los mejores alumnos durante todos los años que permanecieron en la Escuela. Culminó ese idilio ejemplar, cuando en 1960 contrajeron matrimonio. Dos pequeñas hijas alegraban su joven hogar; Carolina, de un año y seis meses, y Pilar, de cinco meses.

La Doctora Juricic, como alumna había trabajado en el Hospital Arriarán, pero su práctica la realizó en el Hospital José Joaquín Aguirre.

Antes de la tragedia, hacía sólo una semana que había llegado de nuevo al viejo Hospital, para una práctica de un mes, luego de la cual obtendría su reconocimiento como anestesista. $\mathrm{Su}$ esposo estaba becado por el SNS en el mismo establecimiento y, ambos dentro de breve plazo, serían trasladados a Valparaíso, donde seguirían trabajando juntos.

La desgracia, puso fin a esta hermosa historia entre dos almas juveniles.

La Doctora Juricic al igual que su esposo era hija de médico. Su padre era el Dr. Víctor Bogoslav Juricic, ex Subdirector del Servicio Nacional de Salud y a la sazón Director en Perú de la Organización Panamericana de la Salud. Su madre, doña Olga Villalón, con una genuina preocupación por la crianza de todos sus hijos.

Ana María Juricic, contaba con 26 años, cuando, después de dos años de haber recibido su título, se convirtió en una de las mártires de la medicina chilena.

\section{Doctor Jaime Palominos Zúñiga}

Mucho podía esperar la Medicina del joven Doctor Jaime Palominos Zúñiga, muerto en la tragedia, cuando recién había cumplido los 27 años de edad. Su dedicación a los estudios, su espíritu de sacrificio, su amor por sus semejantes, su compañerismo y su arrebatadora juventud, lo habían hecho querido de todos los que con él convivieron o que con él trabajaron. Su trágica muerte tronchó una hermosa esperanza para el equipo médico del Hospital Arriarán.

Efectuó sus estudios secundarios en el Ins- tituto Nacional, donde siempre fue un excelente alumno. Destacó en los estudios y en el deporte.

Llegó a la Escuela de Medicina, porque siempre pensó que era en esa carrera donde podía ser más útil a la humanidad. Egresó de la Universidad de Chile, el 3 de mayo de 1961 y de inmediato inició sus labores en la Posta del Hospital Manuel Arriarán, donde había sido contratado recientemente. También había prestado sus servicios profesionalesen el Hospital de Buin.

E1 Dr. Jaime Palominos, era hijo de don Tucapel Palominos, Coronel de Ejército en retiro y de doña Delmira Zúñiga. Tiene un hermano mellizo, Hernán, que es Dentista, y otro, Héctor, que estudió también Medicina en la Universidad de Chile.

\section{Doctor Enrique Zabalaga Justiniano}

Iba a cumplir 42 años de edad, cuando ocurrió la dolorosa tragedia. Nacido en Bolivia, había hecho sus estudios secundarios en su país, para trasladarse a Chile, donde efectuó sus estudios de Medicina en la Escuela de Medicina de la Universidad de Chile. Se nacionalizó como chileno y en 1949 recibió su título, desempeñándose como cirujano especialista en traumatología y ortopedia en la Asistencia Pública de Ñuñoa, en el Instituto Traumatológico y en el Hospital Arriarán.

Casado con doña Gladys Catalán, tenían tres hijos: Roberto, de 12 años; Fernando, de 10 y Rodrigo de 2.

El Dr. Enrique Zabalaga, era hijo de Don Lucio Zabalaga, abogado, ex Ministro de Estado, senador y profesor de la Universidad de Cochabamba. Su madre, doña Olimpia Justiniano. Ambos, junto a sus hermanos, estuvieron junto al lecho del dolor, durante todos los días que duró su estoica agonía. Dos de sus cinco hermanos viven en nuestro país, el arquitecto señor Gustavo Zabalaga, que estudia Odontología en la Universidad de Chile. Sus padres y el resto de su familia, viven en Cochabamba.

Una notable lucidez, luego del accidente, le hizo darse cuenta de la gravedad de su estado, lo que le permitió advertirlo con serenidad y hombría a sus familiares e incluso, hacer in- 
dicaciones sobre el tratamiento a las enfermeras que lo atendían.

Fue el tercer mártir del accidente del Hospital Arriarán.

\section{Doctor Mario Eduardo Torres Kay}

Nació el 13 de junio de 1926, en la ciudad de Los Ángeles, realizando sus estudios en el Liceo de Hombres de esa ciudad. Posteriormente estudió Medicina en la Universidad de Concepción y recibió su título de médico en la Universidad de Chile, en 1950.

Ingresó al Hospital de Carabineros como anestesiólogo, ocupando en la actualidad el cargo de Jefe de Servicio del Departamento de Anestesiología del Hospital de la Institución.

Creador del Departamento de Anestesiología del Hospital Manuel Arriarán, donde prestando sus servicios lo sorprendió el doloroso accidente, que habría de costarle la vida.

Ayudante de la Cátedra de Bacteriología de la Universidad de Concepción y ayudante de la Cátedra de Pediatría y Cirugía Infantil del Profesor Julio Meneghello, en las Universidades de Chile y Católica.

Miembro de la Sociedad de Anestesiología, siendo secretario, vicepresidente y presidente, para el actual período 1963-64.

Becado en la U. de Pittsburg, por un año en el Servicio del Profesor Francis Forbes.

Todos ellos reconocidos como mártires de la Cirugía Pediátrica Chilena.

La Revista Vida Médica de la época señalaba en el volumen XV No 5 de mayo de 1963:

"Rindieron su vida en su misión de derrotar la muerte", acordando bajo la presidencia del Dr Hernán Romero C:

- Pedir al Colegio Médico apruebe la recaudación de una cuota extraordinaria y una erogación voluntaria para ir en ayuda de las víctimas de la tragedia.

- Gestionar ante los Comités Parlamentarios la dictación de una Ley que establezca un Seguro Obligatorio contra Accidentes del Trabajo y Enfermedades Profesionales.

- Recomendar a todos los establecimientos el abandono del ciclopropano como anestésico.

- Declarar ante la opinión pública, que la tragedia del Arriarán y otras recientes, son sín- tomas dolorosos de la precariedad física en que se ven obligados a trabajar los médicos de casi todos los establecimientos del país.

El Dr. Hernán Romero C., Presidente del Colegio Médico, particularmente entristecido por la muerte de la Dra Ana María Juricic señalaba en sus exequias:

"Debi violentarme para cumplir este cometido indeciblemente doloroso. No hay leyenda en la imagen del viejo profesor que deja algo y, a la vez, posee algo en cada uno de los estudiantes que logra individualizar. Ana María y su marido fueron alumnos míos y la imagen de esa pareja de selección surge en mi mente con la misma facilidad que otros recuerdos gratos. Me une a sus padres amistad vieja y genuina y me interesé por ella desde que era niña. El Colegio Médico necesita expresar su sentimiento con la fuerza de un imperativo. Madre, dejó atrás dos criaturas; médico, cayó víctima de un desarrollo de la ciencia de que tanto nos enorgullecemos y que ha traído incalculables beneficios; mujer excepcional, conjugaba promesas y realidad. Se enluta el Colegio porque ha perdido un miembro predilecto. No debió pedirme que lo representara, porque el dolor me aprieta las entrañas y ni siquiera me avergüenzo de las lágrimas que no puedo contener. Por imposible, no intentaría mitigar la pena de Patricio, de sus padres y de los suyos, pero si endulzarla, dándoles noticias de que los médicos acariciamos y conservaremos el recuerdo de Ana María”.

\section{Lancha Ana María Juricic}

Localizada en Achao, de apoyo a su hospital en sus rondas a Llingua, Quenac, Meulín. Construida en astilleros de Valdivia a fines de la década del los 60, con el propósito de destinarla exclusivamente a atención sanitaria en las islas de Chiloé. En 1973 fue desmantelada y destinada a otras funciones. En $1990 \mathrm{el} \mathrm{Mi-}$ nisterio de Salud la rescató para volver a ser destinada como lancha sanitaria en las islas del Departamento de Calbuco, alcanzó aún a navegar en esas maravillosas aguas, formando parte de la encantadora e irresistible magia de Chiloé y sus islas.

En la Sesión ordinaria $N^{\circ} 57$ del miércoles 


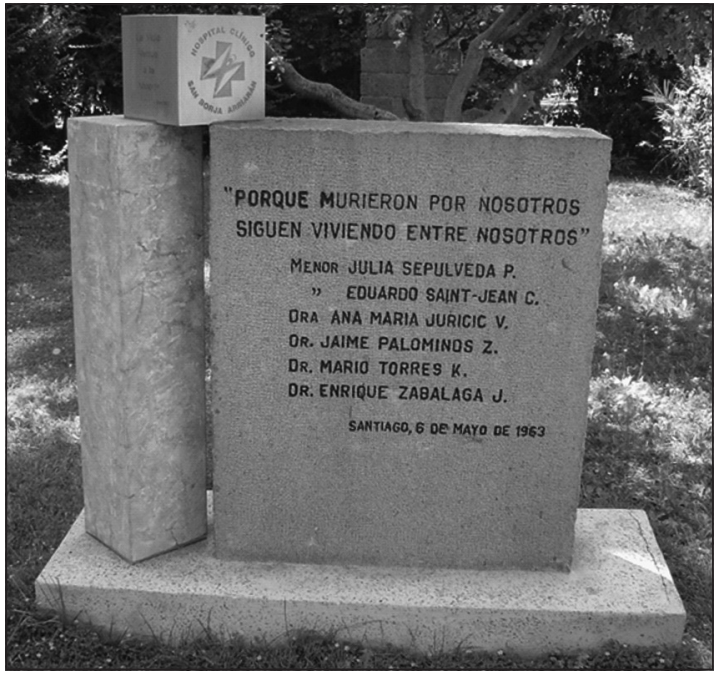

Mártires de la Cirugía infantil chilena.

8 de mayo de 1963, a tan sólo 48 horas de la tragedia, el Diario de Sesiones del Senado de la República de Chile señalaba la intervención del Senador Salvador Allende G., futuro Presidente de Chile "Estuve ayer en los funerales de la Dra. Anita María Juricic. Vi muy de cerca un gran dolor colectivo. Nada pude decir a su padre Bogoslav Juricic, mi antiguo compañero de medicina, ni a su acongojado esposo, también médico. Eran hombres distantes, lejanos, envueltos en un drama tan profundo que inspiraba hondo respeto. Algo similar debe estar ocurriendo en el funeral del Dr. Jaime Palominos Z., en cuanto a emoción. Por los que cayeron y por los que seguirán viviendo una tragedia, hagamos que su historia sea enseñanza para el futuro".

En la misma sesión, el senador Juan Barros Pérez Cotapos, médico pediatra expresaba en su intervención "Las víctimas nos están acusando. $Y$, aunque el recuerdo de ellas-que yo quiero simbolizar en el dulce nombre de Ana María- nos traiga a la mente aquel pensamiento que expresa: "El sándalo perfuma al hacha que lo hiere". Ese recuerdo debe traernos profundas meditaciones. Quien les habla es un médico formado en las salas del Hospital Manuel Arriarán Barros". "Señor Presidente (del Senado), esta tragedia horrenda, por las circunstancias en que ocurrió y por la can- tidad de vidas, ilusiones y potencial humano destruidos en un solo instante, ha sido, más que una explosión en un quirófano, una explosión de toda la ciudadanía".

En el Diario Ilustrado del 9 de mayo de 1963, a pocos días de la tragedia, señala el embajador de EE.UU. "el gobierno de los Estados Unidos enviará a nuestro país los equipos necesarios para dotar una sala de operaciones donados por el pueblo norteamericano, con el fin de reemplazar aquellos destruidos por el trágico accidente que afectó en la mañana del lunes al Hospital de Niños Manuel Arriarán”. Agradecieron el gesto en representación del Presidente de Chile (Sr. Jorge Alessandri Rodríguez), el Ministro de Salud de la época Don Benjamín Cid y el Director del Servicio Nacional de Salud, doctor Gustavo Fricke. Emocionado, el Dr Alberto Veloso N., Jefe del servicio de Cirugía Infantil, recibe el 21 de junio de 1963 cuatro pabellones quirúrgicos. Vislumbraba una señal de recuperación y progreso ante tanta desgracia.

Ya apaciguados los ánimos, El Mercurio del 26 de mayo de 1963, insistía en la importancia de las medidas de control y seguridad hospitalaria como conceptos claves de la gestión y organización de las instituciones de salud, con el propósito fundamental de establecer medidas de prevención primaria en accidentes y desgracias. Rol importante en aquellos tiempos se le asignaba a un funcionario clave: el Jefe Sanitario del establecimiento. En el mismo texto se señalaba la irrupción de nuevos y modernos anestésicos, de mayor efectividad y menor riesgo.

El Colegio Médico de Chile señaló en la conmemoración de dicha tragedia en los patios del Hospital Clínico San Borja Arriarán, que el día 6 de mayo ha sido declarado "Día del Médico Mártir". En dicha oportunidad la décima Compañía de Bomberos les rindió honores, se plantó un árbol junto al Memorial y se colocó una placa con el nombre de los médicos mártires en los pabellones de cirugía del hospital.

Los balones de ciclopropano fueron retirados para siempre de todos los hospitales del país. 